\title{
Editorial
}

\section{Advances in Lightning Protection Research}

\author{
Vladimir A. Rakov ${ }^{*}, 1 \S$ and Fridolin Heidler ${ }^{2, \S}$ \\ ${ }^{I}$ Department of Electrical and Computer Engineering, University of Florida, Gainesville, FL 32611, USA \\ ${ }^{2}$ Department of Electrical and Computer Engineering, University of the Federal Armed Forces Munich, Werner- \\ Heisenberg-Weg 35, D-85577 Neubiberg, Germany
}

Lightning is a spectacular natural phenomenon, but it is also a severe hazard to human life and to various objects and systems. Worldwide, there are a few thousand lightning deaths and tens of thousands of lightning injuries per year. Lightning initiates many forest fires, and over $30 \%$ of all electric power failures are lightning related. A lightning strike to an unprotected or inadequately protected object can be catastrophic.

This Special Issue of Journal of Lightning Research is dedicated to the 30th International Conference on Lightning Protection (ICLP), held in Cagliari (Italy) on September 1216,2010 . The primary objective of this conference is to provide an interdisciplinary forum for the exchange of scientific knowledge and information in the fields of lightning physics, lightning protection, and related areas. A total of 228 papers were presented and discussed in 38 oral sessions (166 papers) and in 2 poster sessions (62 papers) at ICLP 2012, of which 12 are included in this Special

*Address correspondence to this author at the Department of Electrical and Computer Engineering, University of Florida, Gainesville, FL 32611, USA; Tel: 352-392-4242; E-mail: rakov@ece.ufl.edu

${ }^{\S}$ Guest Editors
Issue. They were each expanded by the authors relative to the conference version and recommended for publication by at least two qualified reviewers. A number of other papers presented at ICLP 2010 are published or to be published in Special Issues of two other journals, Electric Power Systems Research, Vol. 85, April 2012, pages 1-94 (www.elsevier. com/locate/epsr) and Atmospheric Research (http://www. journals.elsevier.com/atmospheric-research/). The papers included in this Special Issue cover a broad range of topics from lightning modeling to practical lightning protection problems to medical aspects of lightning.

The following is a list of countries (in alphabetical order) represented in this Special Issue: Australia, Belgium, Canada, Denmark, Hungary, Italy, Japan, Serbia, Spain, Sweden, and Switzerland. Some papers resulted from collaboration between different research groups.

We would like to thank all the authors for accepting our invitation to submit their papers to the Special Issue and meeting all the deadlines. We would also like to acknowledge support of Prof. Vernon Cooray (EIC) during the entire process of preparing this issue. Ms. Mahwish Siddiqui, Editorial Manager, and Dr. Mehreen Khan, Assistant Manager of Bentham Science Publishers helped to put it all together.

(C) Rakov and Heidler; Licensee Bentham Open.

This is an open access article licensed under the terms of the Creative Commons Attribution Non-Commercial License (http://creativecommons.org/licenses/by-nc/3.0/) which permits unrestricted, non-commercial use, distribution and reproduction in any medium, provided the work is properly cited. 